Matthias Habeler, Herbert H. Lindner and Bernhard Redl*

\title{
A role of heparan sulphate proteoglycan in the cellular uptake of lipocalins B-lactoglobulin and allergen Fel d 4
}

https://doi.org/10.1515/hsz-2020-0132

Received February 11, 2020; accepted March 16, 2020; published online July 16, 2020

\begin{abstract}
Lipocalins, small extracellular hydrophobic molecule carriers, can be internalized by a variety of different cells. However, to date receptors have only been identified for human lipocalins. Here, we specifically investigated uptake mechanisms for lipocalins B-lactoglobulin and Fel d 4 in HeLa and Chinese hamster ovary (CHO) cells. We provide evidence that cell surface heparan sulphate proteoglycan is essential for internalization of these lipocalins. In HeLa cells, lipocalin uptake was inhibited by competition with soluble heparin, enzymatic digestion of cellular heparan sulphate by heparinase and inhibition of its biosynthesis by sodium chlorate. Biochemical studies by heparin affinity chromatography and colocalization studies further supported a role of heparan sulphate proteoglycan in lipocalin uptake. Finally, lipocalin uptake was blocked in $\mathrm{CHO}$ mutant cells defective in glycosaminoglycan biosynthesis whereas in wildtype cells it was clearly detectable. Thus, cell surface heparan sulphate proteoglycan represents a novel component absolutely participating in the cellular uptake of some lipocalins.
\end{abstract}

Keywords: cellular uptake; heparan sulphate; heparinase treatment; lipocalin; proteoglycan.

\section{Introduction}

Lipocalins were found to be important carriers of hydrophobic molecules in many species and there is clear evidence that they are involved in a variety of physiological processes such as inflammation, infection, immunity, development, iron metabolism, lipid metabolism and

*Corresponding author: Bernhard Redl, Institute of Molecular Biology, Medical University Innsbruck, Innrain 80, A-6020, Innsbruck, Austria, e-mail: Bernhard.Redl@i-med.ac.at. https://orcid.org/00000003-4301-0797

Matthias Habeler: Institute of Molecular Biology, Medical University Innsbruck, Innrain 80, A-6020, Innsbruck, Austria Herbert H. Lindner: Institute of Clinical Biochemistry, Medical University Innsbruck, Innrain 80, A-6020, Innsbruck, Austria chemosensation (Akerstrom et al. 2006; Brennan and Kendrick 2006; Chakraborty et al. 2012; Conde et al. 2011; Correnti and Strong 2012; Johnson and Wessling-Resnick 2012; Zhao et al. 2012; Kim et al. 2009; Koistinen et al. 2009; Pan et al. 2011; Ruiz et al. 2013; Chamero et al. 2007). They also play a role in reactions of organisms to various stress conditions and in the pathways of signal transduction (Charron et al. 2008; Ganfornina et al. 2008; Lechner et al. 2001; Mulligan et al. 2012; Olsson et al. 2008). However, there is little knowledge regarding the molecular mechanisms by which lipocalins exert their biological effects. Although it is well accepted that lipocalins can bind to specific cellular receptors (Flower 2000), so far only a few human receptors have been identified, which may be functionally grouped into three classes (Burke et al. 2006). Most receptors seem to function in an endocytic manner, mediating uptake of the entire lipocalin-ligand complex. These include megalin, lipocalin-1-interacting membrane receptor (LIMR/ LMBR1L), the Lcn-2 receptor NGalR/24p3R/SLC22a17 and basigin (Devireddy et al. 2005; Leheste et al. 1999; Najyb et al. 2015; Wojnar et al. 2001). While megalin and NGalR display promiscuous ligand binding (Christensen and Birn 2002; Langelueddecke et al. 2012), the others possess specific lipocalin binding activity. Another type of lipocalin receptor is STRA6 (Kawaguchi et al. 2007), a receptor for retinol-binding 24p3protein (RBP). The RBPSTRA6 system represents a small molecule delivery mechanism that involves an extracellular carrier protein but does not depend on endocytosis (Redondo et al. 2008). A third group is typified by CD 45 , a major protein tyrosine phosphatase receptor, which has been described to bind glycodelin/PP14, an immunoregulatory lipocalin (Rachmilewitz et al. 2003). Thus, the role of these receptors will likely vary according to the physiological function of their lipocalin ligand. In a preliminary study, we found that two animal lipocalins, bovine $\beta$-lactoglobulin (BLG) (Kontopidis et al. 2004; Sawyer and Kontopidis 2000) and cat Fel d 4 (Papes et al. 2010; Smith et al. 2004), were internalized by a variety of cells, including several human cell lines. However, to date almost no knowledge on the uptake of exogenous lipocalins exists despite humans being exposed to these proteins daily. 
Both lipocalins are relevant human allergens. In addition, BLG was demonstrated to be a potent stimulator of proliferation (Tai et al. 2016) and is used as a nanocarrier for delivering pharmacological agents (Bijari et al. 2019; Shafaei et al. 2017). Therefore, in this work we aimed to identify cell surface components responsible for the cellular uptake of these lipocalins. Here, we present clear evidence that cell-surface heparan sulphate proteoglycan (HSPG) is essential for their internalization and, therefore, represents a novel component involved in lipocalin uptake.

\section{Results}

\section{Membrane crosslinking studies indicate close neighbourhood of lipocalins and HSPG binding proteins}

Previous studies demonstrated that exogenous animal lipocalins can be internalized by different human cell lines. An example showing uptake and colocalization of bovine BLG and feline Fel d 4 in HeLa cells and CHO cells is depicted in Figure 1. The near perfect colocalization of both proteins in both cell lines, together with the fact that Fel d 4 internalization could be blocked by an excess of BLG (see Supplementary Figure 1), indicated a common uptake mechanism. Therefore, in a first attempt we sought to isolate the corresponding receptor by a crosslinking approach using biotinylated lipocalins which we crosslinked to HeLa cell membranes using SDAD photochemical crosslinker. Then, membranes were solubilized and lipocalin bait-prey complexes were isolated by affinity pull-down and analysed by SDS-PAGE. A silver-stained gel displaying proteins captured by crosslinking lipocalin baits to HeLa membranes is shown in Figure 2. A distinct pattern of protein bands ranging from about 30 to $100 \mathrm{kDa}$ is visible irrespective of lipocalin bait used, although band intensities were weaker for Fel $\mathrm{d} 4$. The most prominent protein bands were excised and identified by mass spectrometry (Table 1). Several heat shock proteins (HSP90, BIP, mtHSP70 and HSP60) and Calnexin, which usually locate to the endoplasmic reticulum, mitochondria and cytosol, were found as well as the cytoskeletal proteins Actin, Vimentin and Emerin. This result was unexpected, but we noticed that a very similar pattern of proteins was identified in an attempt to crosslink lipocalin-type prostaglandin D synthase (PGDS) to NIH3T3 cells (Suk 2012). Later, PGDS was indeed demonstrated to directly interact with cellular and recombinant HSP90 (Binda et al. 2014). Moreover, there is increasing evidence that HSPs can traffic to the cell surface and reinternalize later (Crowe et al. 2017; Okazaki et al. 2000), a mechanism which might be relevant for cellular uptake of PGDS and other lipocalins. To investigate whether BLG and Fel d 4 also directly interact with HSP90, we recombinantly expressed it from $E$. coli and performed co-affinity precipitation experiments. However, we observed no

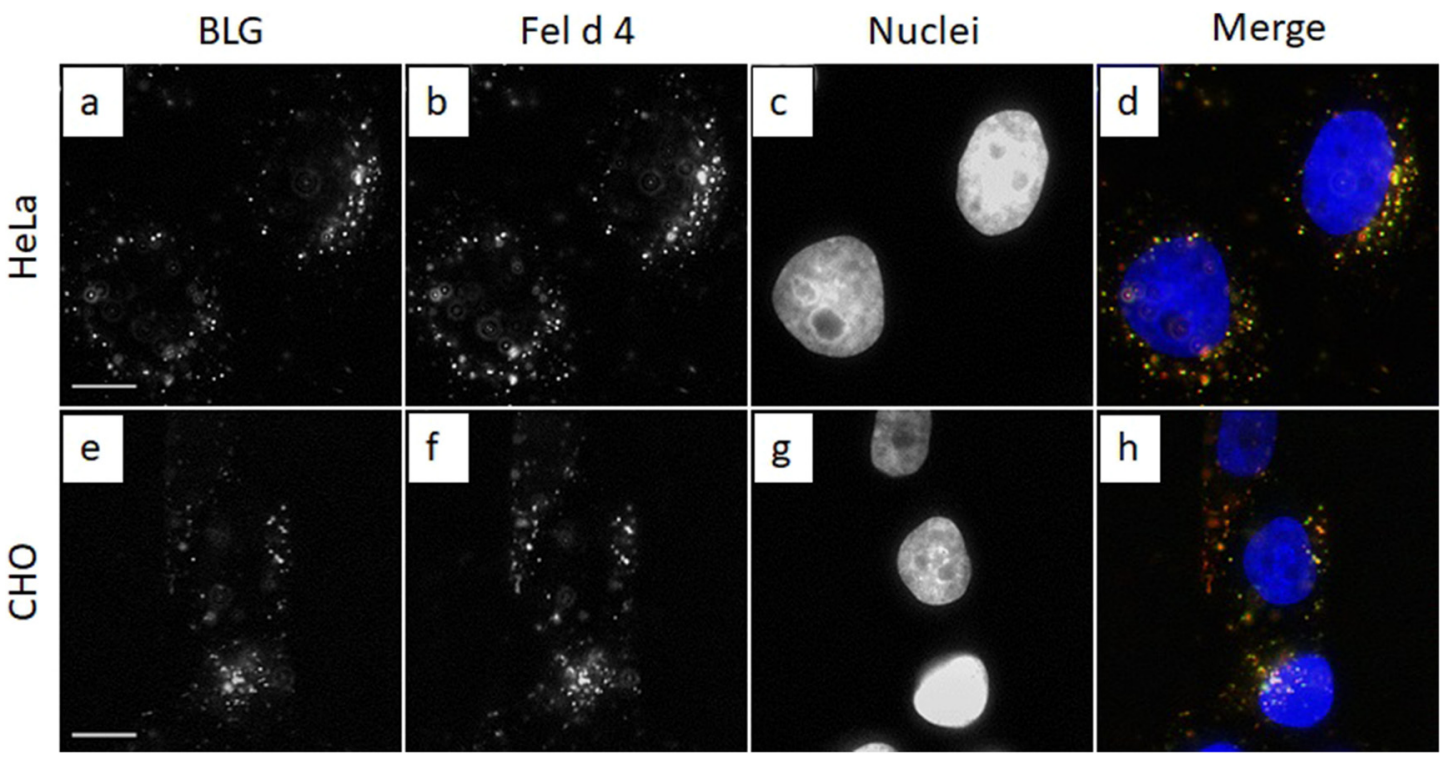

Figure 1: Uptake and colocalization of BLG (a, e) and Fel d 4 (b, f) in HeLa and CHO cells, respectively. Cells were simultaneously incubated with $25 \mu \mathrm{g} / \mathrm{mL}$ Carboxyfluorescein-BLG and $25 \mu \mathrm{g} / \mathrm{mL}$ Hilyte Fluor 594-Fel d 4 in serum-free medium for 2 hours, then fixed in paraformaldehyde and counterstained for nuclei with DAPI (c, g). Merged images (d, h). Scale bar is $10 \mu \mathrm{m}$. 


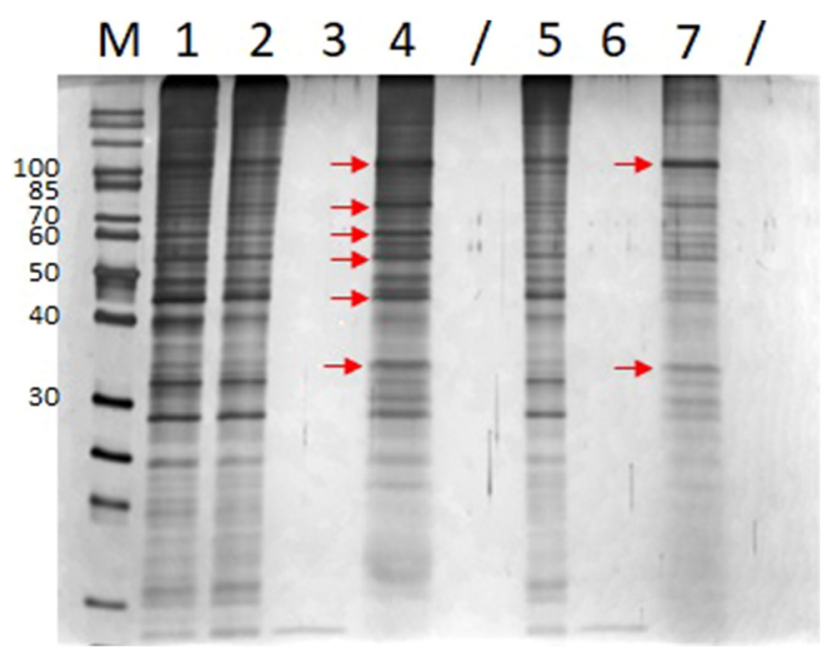

Figure 2: Proteins captured by crosslinking either BLG or Fel d 4 to HeLa membranes. Samples were run on $12 \%$ SDS-PAGE and visualized by mass spectrometry-compatible silver staining. Protein bands indicated by arrows were excised and identified by mass spectrometry (refer to Table 1 ). Lanes correspond to molecular size marker (M), $200 \mathrm{ng}$ HeLa membrane proteins (1), supernatant, final wash and eluate from BLG (2, 3 and 4$)$ and Fel d 4 (5, 6 and 7) crosslink samples respectively.

direct interaction of HSP90 with BLG or Fel d 4 (see Supplementary Figure 2).

Thus, we speculated that crosslinking of lipocalin baits to cell-surface HSP90 might result from indirect interaction. Heat shock proteins (HSPs) usually locate to the endoplasmic reticulum, mitochondria and cytosol, but have also been found on the cell surface (Bzowska et al. 2017; Gonzalez-Gronow et al. 2009; Soltys and Gupta 1996). These cell-surface exposed HSPs may be bound to heparan sulphate, which has been demonstrated for HSP90 (Snigireva et al. 2015), as they often possess heparin binding activity (Harada et al. 2014; Itoh and Tashima 1993; Ménoret and Bell 2000). This assumption was further supported by the high abundance of Calnexin, an endoplasmic reticulum chaperone and lectin, that has been found to associate with cell surface glycoproteins in HeLa cells (Okazaki et al. 2000). In sum, these indications encouraged us to investigate a potential interaction of lipocalins and heparan sulphate proteoglycan (HSPG).

\section{Lipocalins BLG and Fel $\mathrm{d} 4$ bind to heparin}

We first tested whether lipocalins potentially possess heparin or heparan sulphate binding affinity at physiological pH by performing heparin affinity chromatography. Despite
Table 1: Mass spectrometric identification of silver-stained bands from Figure 2.

\begin{tabular}{|c|c|c|c|}
\hline & Protein & $\begin{array}{r}\text { Sum PEP } \\
\text { score }\end{array}$ & \#Peptides \\
\hline \multirow[t]{12}{*}{ Hela + BLG } & $\begin{array}{l}\text { Stress-70 protein, mito- } \\
\text { chondrial }\end{array}$ & 31.36 & 10 \\
\hline & Actin, cytoplasmic 1 & 28.87 & 7 \\
\hline & Calnexin & 21.99 & 8 \\
\hline & $\begin{array}{l}60 \mathrm{kDa} \text { heat shock protein, } \\
\text { mitochondrial }\end{array}$ & 15.97 & 5 \\
\hline & $\begin{array}{l}\text { Heat shock protein HSP90- } \\
\text { beta }\end{array}$ & 14.77 & 6 \\
\hline & $\begin{array}{l}\text { Heat shock protein HSP90- } \\
\text { alpha }\end{array}$ & 12.39 & 4 \\
\hline & $\begin{array}{l}\text { Transferrin receptor protein } \\
\quad 1\end{array}$ & 11.05 & 3 \\
\hline & $\begin{array}{l}\text { Endoplasmic reticulum } \\
\text { chaperone BIP }\end{array}$ & 10.64 & 4 \\
\hline & Vimentin & 10.52 & 5 \\
\hline & Emerin & 8.78 & 3 \\
\hline & $\begin{array}{l}\text { L-lactate dehydrogenase } \mathrm{A} \\
\text { chain }\end{array}$ & 8.68 & 3 \\
\hline & $\begin{array}{l}\text { Heat shock cognate } 71 \mathrm{kDa} \\
\text { protein }\end{array}$ & 7.74 & 3 \\
\hline \multirow{4}{*}{$\begin{array}{l}\text { Hela }+ \text { Fel } \\
\quad \text { d } 4\end{array}$} & Calnexin & 32.25 & 13 \\
\hline & $\begin{array}{l}\text { Heat shock protein HSP90- } \\
\text { beta }\end{array}$ & 14.78 & 5 \\
\hline & $\begin{array}{l}\text { Heat shock protein HSP90- } \\
\text { alpha }\end{array}$ & 10.72 & 4 \\
\hline & Emerin & 10.06 & 4 \\
\hline
\end{tabular}

The values were adjusted to exclude background proteins also found in an empty control slice from the same polyacrylamide gel.

net negative charge both BLG and Fel $\mathrm{d} 4$ showed specific retention on a heparin sepharose column (Figure 3) indicating the presence of a heparin-binding motif. In contrast, human Lcn-1, which is similar in molecular weight, structure, isoelectric point and number of basic amino acid residues, did not bind. This observation suggested that HSPG may play a role in binding and internalization of lipocalins.

\section{Lipocalin uptake requires cell surface HSPG in HeLa cells}

To verify the above hypothesis, we investigated the effects of different reagents impairing the structure of cellular HSPGs on the internalization of lipocalins. In the first approach, we tested the influence of soluble heparin, a polysaccharide closely related to heparan sulphate, on the endocytosis of BLG (Figure 4). For comparison we used lipocalin-1 (Lcn-1), which is internalized via its specific receptor LIMR (Wojnar et al. 2001). Cellular uptake of BLG 
and Lcn-1 was investigated in untreated HeLa cells or cells pre-treated with heparin prior to the addition of fluorescently labelled lipocalins. Untreated control cells display a circular, diffuse Lcn-1 fluorescence surrounding the nucleus while a more distinct, punctate, non-overlapping BLG fluorescence pattern indicates a different endocytosis route (Figure 4A). Following treatment with heparin, the Lcn-1 signal remains unchanged, which was also evident from image quantification analysis (Figure 4B). However, the vesicular BLG fluorescence is almost completely lost. A similar effect of heparin treatment was also observed on the endocytosis of Fel $\mathrm{d} 4$ (Figure 5). Overall, image quantification revealed a reduction in both BLG and Fel $\mathrm{d} 4$ uptake of about $75 \%$ after heparin treatment (Figure 8).

Next, we treated HeLa cells with different concentrations of heparinase $(0.5,2.0$ and $10.0 \mathrm{U} / \mathrm{mL})$ for $30 \mathrm{~min}$ prior to the addition of labelled lipocalins. Again, uptake of BLG (Figure 6A) and Fel d 4 (Figure 6B) was markedly reduced. Similar to the results obtained from heparin blocking experiments described above, the amount and intensity of BLG and Fel d 4 fluorescent vesicles was reduced by about $70 \%$ in a concentration-dependent manner in comparison to untreated control cells (Figure 8).

Third, we pre-incubated HeLa cells overnight with sodium chlorate, an inhibitor of sulphate transfer onto glycosaminoglycans (GAGs), and then performed uptake experiments. This treatment also resulted in severe reduction of BLG and Fel d 4 uptake (Figures 7A,B). Image quantification demonstrated that the intracellular fluorescence was diminished by about $80 \%$ for both proteins (Figure 8).

In sum, these results clearly demonstrated that BLG and Fel d 4 internalization in HeLa cells depends on binding to cell surface heparan sulphate proteoglycan, which is, however, not involved in Lcn-1 uptake.

\section{Lipocalin uptake is inhibited in glycosaminoglycan-deficient $\mathrm{CHO}$ cells}

Furthermore, we investigated the endocytosis of BLG and Fel d 4 in wild-type and glycosaminoglycan-deficient deletion mutant (pgsA-745) CHO cells (Figure 9). These mutant cells have a defect in xylosyltransferase,

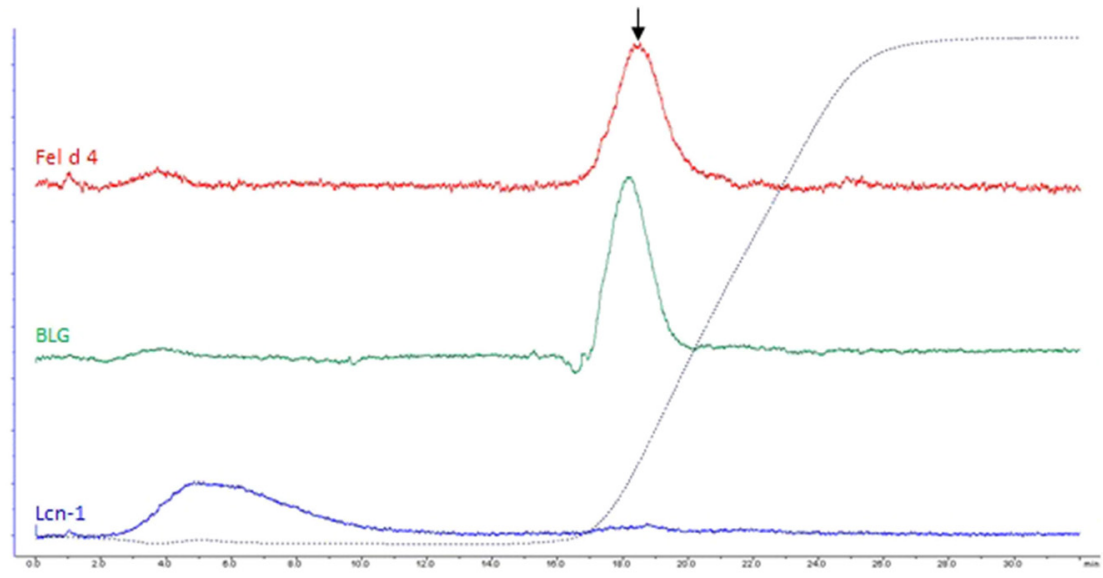

A

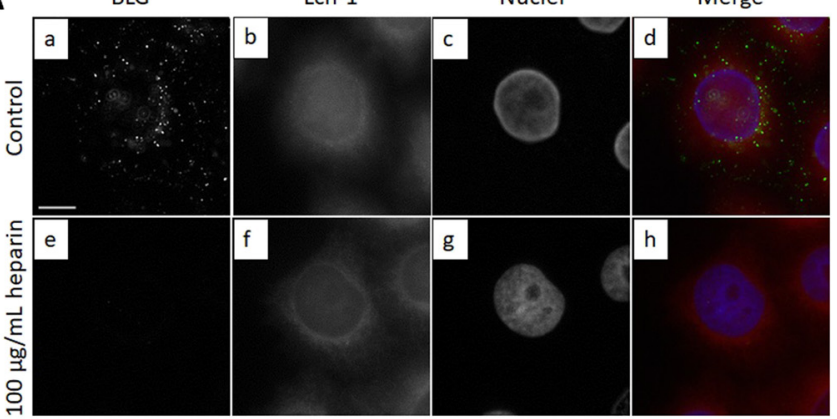

B

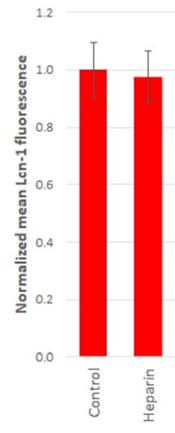

Figure 3: Heparin-affinity chromatography of Lcn-1, BLG and Fel d 4. $200 \mu \mathrm{g}$ of each lipocalin were applied to a heparin sepharose column in low salt binding buffer $\mathrm{pH} 7.2$ and eluted by a linear sodium chloride gradient (dashed line). BLG and Fel $\mathrm{d} 4$ were retained and eluted at approximately $100 \mathrm{mM}$ sodium chloride while Lcn-1 did not show any heparin binding.
Figure 4: (A) Effect of heparin treatment on the internalization of BLG and Lcn-1 in HeLa cells. (a-d) untreated control cells. (e-h) cells treated with $100 \mu \mathrm{g} / \mathrm{mL}$ heparin. Cells were incubated with equal amounts of labelled lipocalins. Scale bar is $10 \mu \mathrm{m}$. (B) Quantification of Lcn-1 internalization in untreated and heparin treated cells (normalized mean fluorescence intensity \pm 1 SD, analysed by imageJ). 
the first sugar transfer in GAG synthesis, and do not produce GAG. Wild-type cells display a clear accumulation of fluorescence signal in a perinuclear compartment after 1 hour of incubation with either protein. In contrast, GAG-deletion mutant cells hardly contain any fluorescence signal. This observation again suggests a vital role of GAGs in the endocytosis of BLG and Fel $\mathrm{d} 4$ lipocalins.

\section{HSPG and BLG colocalize on the plasma membrane of HeLa cells}

Finally, we were able to detect colocalization of BLG and heparan sulphate on the plasma membrane of HeLa cells by immunostaining (Figure 10). Cell surface HSPG stained in a punctate pattern, which displayed a high degree of colocalization with BLG fluorescence. Additionally,

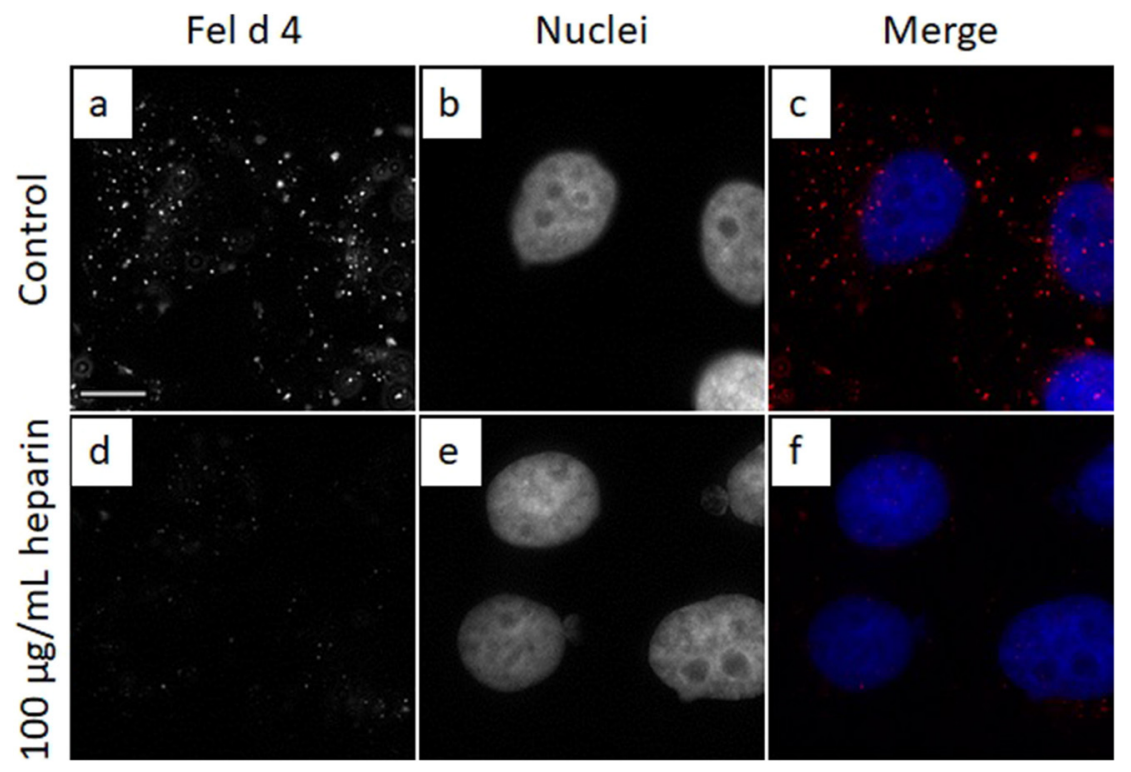

Figure 5: Effect of heparin treatment on the internalization of Fel d 4 (red) in Hela cells. $(a-c)$ untreated control cells. (d-f) cells treated with $100 \mu \mathrm{g} / \mathrm{mL}$ heparin. Scale bar represents $10 \mu \mathrm{m}$.
A

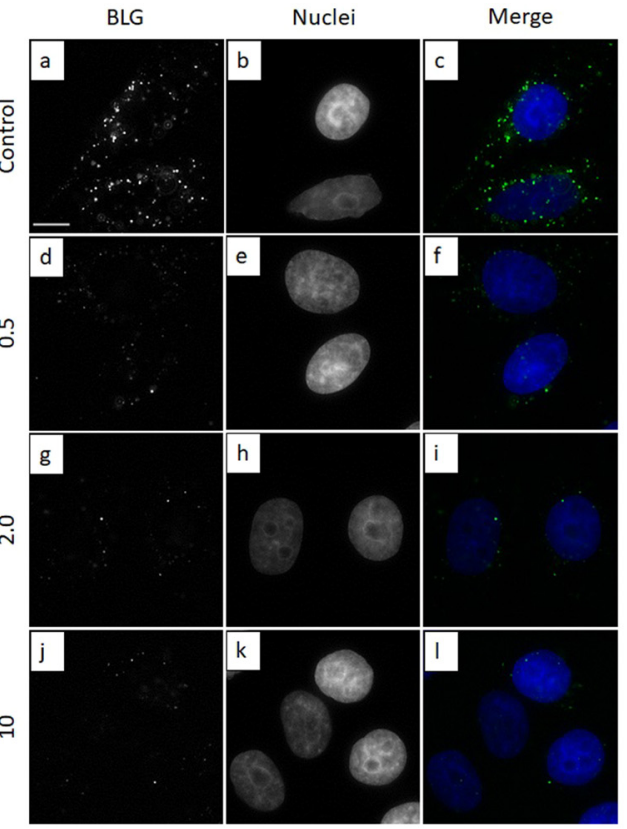

B

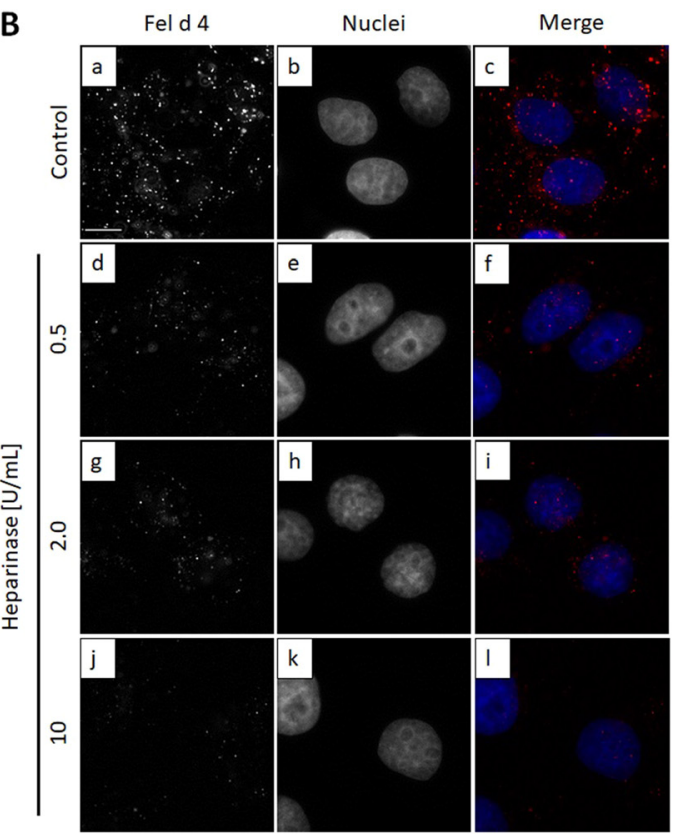

Figure 6: (A) Effect of heparinase treatment on the internalization of BLG in Hela cells. (a-c) untreated control cells. Cells pre-treated with 0.5 $(\mathrm{d}-\mathrm{f}$ ), 2.0 (g-i) or $10.0(\mathrm{j}-\mathrm{l}) \mathrm{U} / \mathrm{mL}$ heparinase for $30 \mathrm{~min}$. Scale bar is $10 \mu \mathrm{m}$. (B) Effect of heparinase treatment on the internalization of Fel $\mathrm{d} 4 \mathrm{in}$ Hela cells. $(a-c)$ untreated control cells. Cells pre-treated with $0.5(d-f), 2.0(g-i)$ or $10.0(j-l) \mathrm{U} / \mathrm{mL}$ heparinase for 30 min. Scale bar represents $10 \mu \mathrm{m}$. 
A

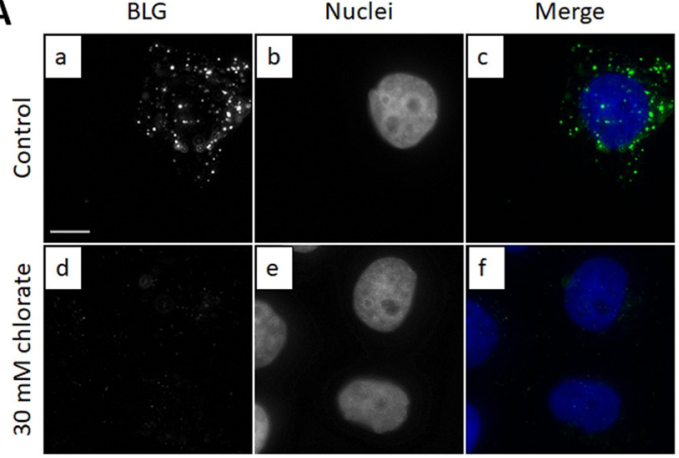

B

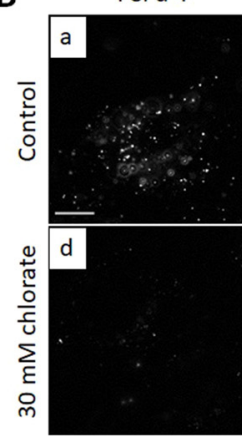

Nuclei

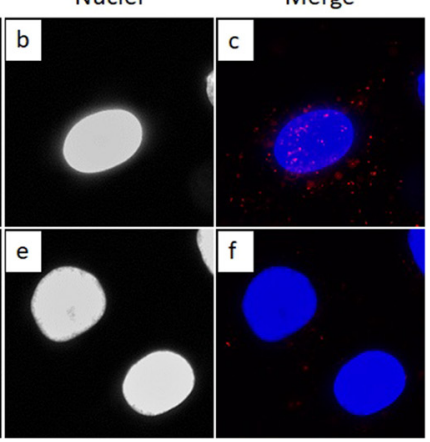

Figure 7: (A) Effect of $\mathrm{NaClO}_{3}$ treatment on the internalization of $\mathrm{BLG}$ in HeLa cells. (a-c) untreated control cells. (d-f) Cells pre-treated with $30 \mathrm{mM} \mathrm{NaClO}{ }_{3}$ overnight. Scale bar is $10 \mu \mathrm{m}$. (B) Effect of $\mathrm{NaClO}_{3}$ treatment on the internalization of Fel d 4 in HeLa cells. (a-c) Untreated control cells. $(\mathrm{d}-\mathrm{f})$ Cells pre-treated with $30 \mathrm{mM} \mathrm{NaClO}$ overnight. Scale bar is $10 \mu \mathrm{m}$.

enrichment of BLG is also observed within a perinuclear compartment while the heparan sulphate antibody used in this study was not internalized but was only detectable on the cell surface. The colocalization of heparan sulphate and BLG signals on the plasma membrane further substantiates our assumption of heparan sulphate requirement for lipocalin internalization. This observation is in agreement with our blocking experiments using heparin, heparinase and sodium chlorate as well as the results obtained from the GAG-deletion mutant CHO line pgsA-745.

\section{Discussion}

By several different experiments, we have clearly demonstrated that HSPG is essential for the cellular uptake of lipocalins BLG and Fel d 4. Nevertheless, the results of our crosslinking approach require some further discussion. Although the SDAD crosslinker applied in our experimental approach should theoretically be able to link not only protein-protein complexes but any bio-macromolecules (e.g. protein-GAG), we only succeeded in isolating membraneassociated proteins, such as HSPs, Calnexin, Vimentin and Emerin. All of them have been described to locate in cholesterol-rich membrane regions or lipid rafts or to be constitutes of HSPG complexes (Harada et al. 2014; PodymaInoue et al. 2016; Snigireva et al. 2015). Mitochondrial HSC70 has even been assigned a crucial role in endocytic HSPGvesicles (Wittrup et al. 2010). These proteins most likely do not interact directly with our baits but rather localize in close proximity to the actual lipocalin receptor component. Furthermore, the following reason might have hampered the isolation of lipocalin-proteoglycan complexes in our experiments. Proteoglycans consist of a core protein and one to several attached glycosaminoglycan chains resulting in a complex, heterogeneous structure which may run in poorly focused bands in SDS-PAGE. Since we have analysed only prominent protein bands, we might have failed to identify such complexes.

In general, there is increasing evidence for a role of HSPG as a cell surface endocytosis receptor (Christianson and Belting 2014). It was shown that cell penetrating peptides (Poon and Gariépy 2007), polycation-nucleic acid complexes (Mounkes et al. 1998), viruses (Zhu et al. 2011), lipoproteins, growth factors and morphogens among other ligands (Ori et al. 2008) enter cells through HSPG-mediated endocytosis. In addition, HSPG serves as a major receptor for human eosinophil cationic protein, an RNase A superfamily member, highly implicated in asthma pathology, due to its toxicity on bronchial epithelial cells (Fan et al. 2007). Similarly, the transactivator protein Tat of human HIV-1 specifically interacts with HSPG, which is absolutely required for viral particle uptake (Fittipaldi et al. 2003). The mechanism of internalization and trafficking of cell surface proteoglycans and their ligands was also investigated in detail (Payne et al. 2007). In this context, it is not fully surprising to find members of the lipocalin family to be targets of HSPGs. Nevertheless, HSPG-mediated endocytosis represents a novel mechanism for cellular lipocalin uptake, which may not only be restricted to BLG and Fel d 4. Lcn-2 has previously been shown to bind to heparin sepharose (Yang et al.2002), while lipocalin PP14/glycodelin interacts with cell surface glycoproteins (Rachmilewitz et al. 2003). Since HSPGs are ubiquitously expressed by most mammalian cell types, such heparin-binding lipocalins may enter numerous cells. This finding is of special interest as BLG has been recently used as a nanocarrier for delivering biological agents such as chemotherapeutics (Bijari et al. 2019; Shafaei et al. 2017), and has also been 
A

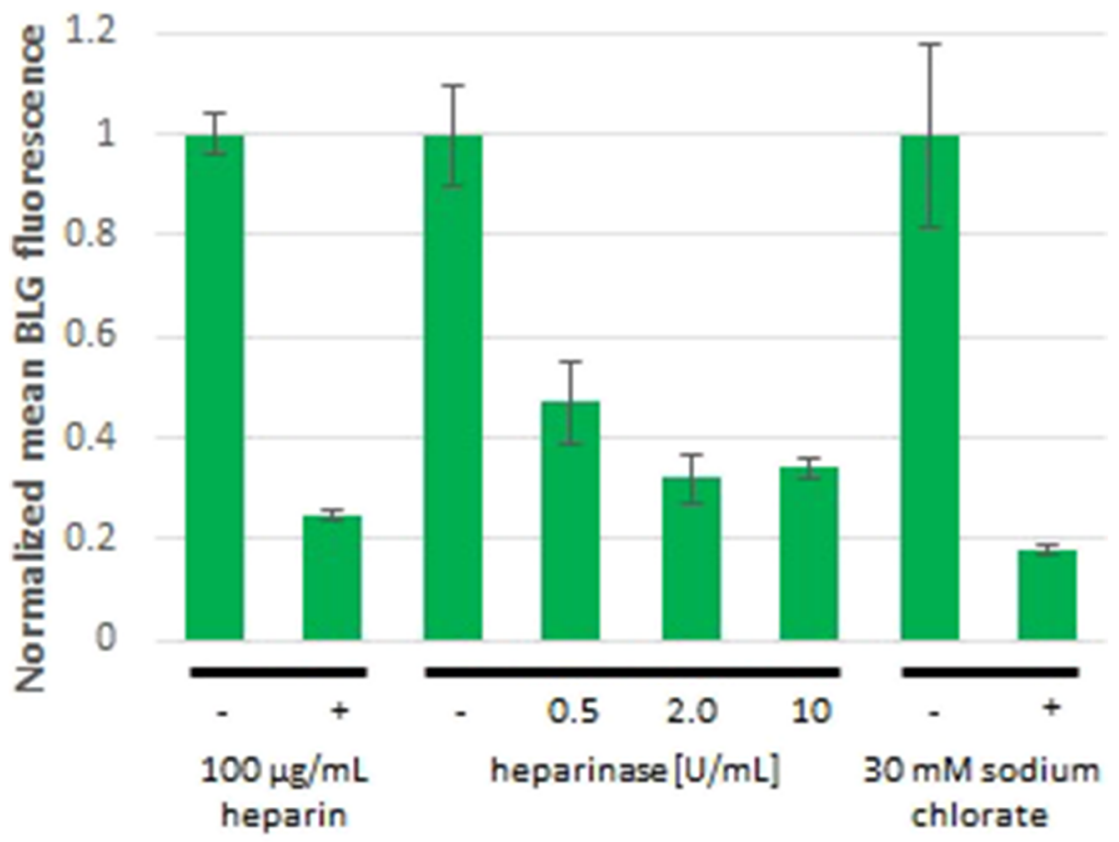

B

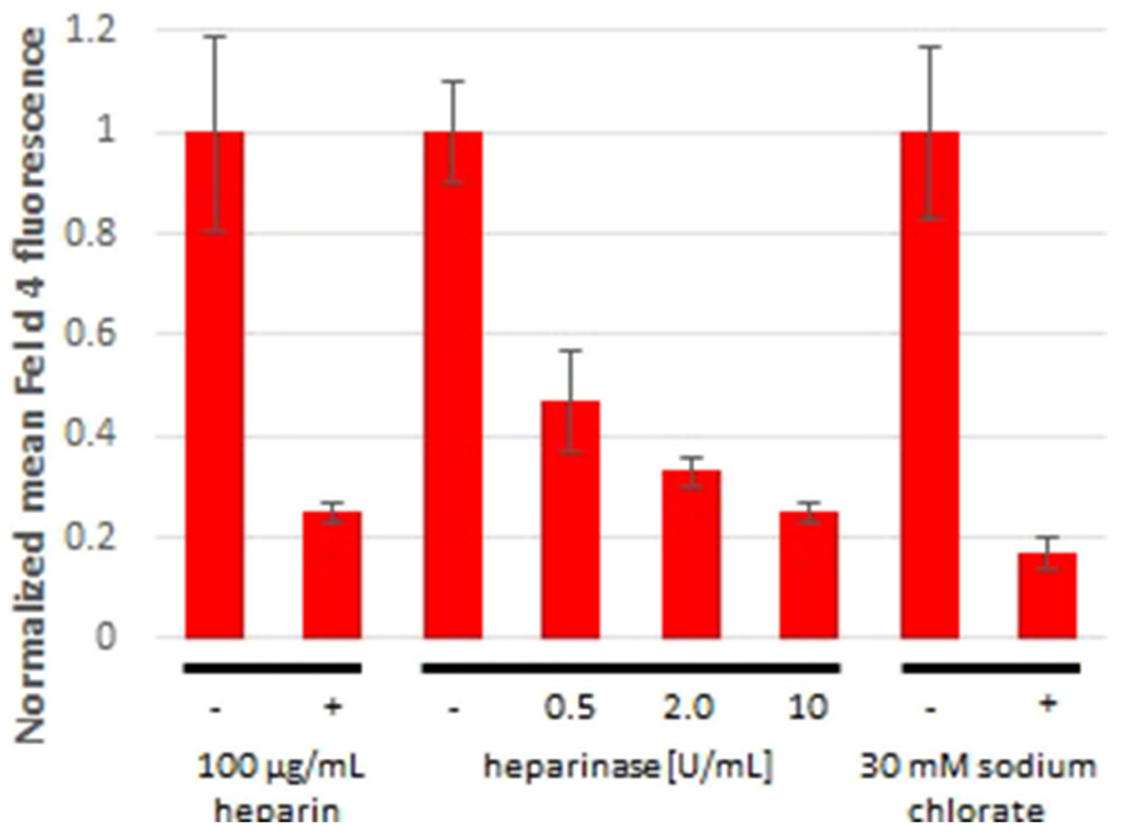

Figure 8: Quantification of the effect of HSPG-disturbing treatment on the internalization of lipocalins in HeLa cells. (A) fluorescence intensities of BLG. (B) fluorescence intensities of Fel $d 4$. Fluorescence signals were quantified by Image,, normalized to control levels and depicted as mean signal intensity \pm 1 SD (obtained from at least 3 cells per image). Original, uncut images, which the presented quantification is based on, are depicted in Supplementary data (Supplementary Figures 3-8).

attributed cytoproliferative effects (Tai et al. 2016). In addition, it was demonstrated that antigens with inherent heparin-binding affinity are supported more efficiently by the immune system (Léonetti et al. 2010), an effect which might shed some light on the enigmatic allergenicity of lipocalins. In addition, it should also be considered that exogenous lipocalins may shuttle potentially harmful hydrophobic ligands via this mechanism. 


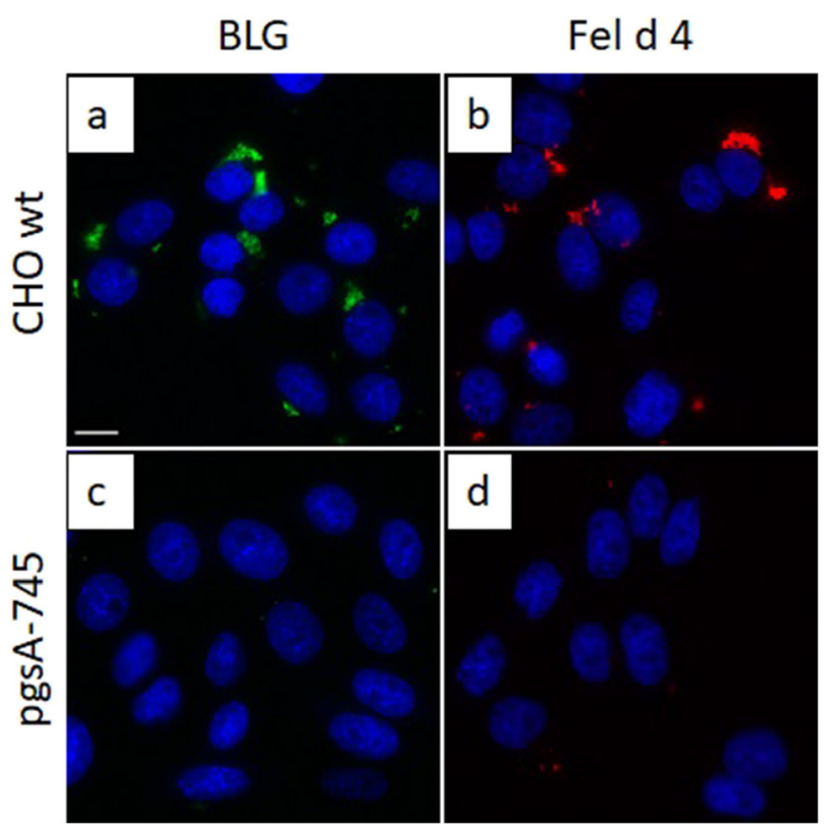

Figure 9: Uptake studies of BLG (green) and Fel d 4 (red) in wt $\mathrm{CHO}$ cells (top row) and pgsA-745 mutant $\mathrm{CHO}$ cells (bottom row) lacking GAG biosynthesis. Scale bar repreesents $10 \mu \mathrm{m}$. In some mutant cells a faint red signal (panel d) is located on the cell surface and might be due to unspecific binding to other cell surface components.

From our experiments, we cannot rule out the possibility that other classes of the glycosaminoglycan family (which includes heparan sulphate, chondroitin sulphate, dermatan sulphate, keratan sulphate and hyaluronate) may also participate in lipocalin binding and uptake. Soluble heparin was highly efficient in blocking uptake of both BLG and Fel $\mathrm{d} 4$ in HeLa cells but is probably not an exclusive inhibitor of HSPG-ligand interaction. Heparinase treatment, which is highly specific for HSPGs, was slightly less effective in uptake inhibition (about 70\% inhibition compared to about $75 \%$ by heparin and about $80 \%$ by sodium chlorate).
Thus, it is evident that HSPGs are the major component responsible for the lipocalin uptake. Nevertheless, a residual uptake activity, especially in case of BLG, may result from participation of other GAG classes, which are not susceptible to heparinase digestion. Such a mechanism involving both heparan sulphate and chondroitin sulphate is for instance responsible for the internalization of a DNA-binding antibody in HeLa cells (Park et al. 2017).

In addition, we also cannot rule out the possibility that additional components, such as other HSPG binding proteins are involved in lipocalin uptake. However, our results demonstrate that proteoglycans are essential for uptake of BLG and Feld $\mathrm{d} 4$ in the cell lines investigated. Nevertheless, in other cells additional, HSPG-independent uptake mechanisms might exist. In a previous study, we found BLG to be internalized via LIMR, the Lcn-1 receptor (Fluckinger et al. 2008). However, it should be mentioned that this former finding was based on experiments in yeast cells overexpressing recombinant LIMR, which may be a highly artificial system. Concerning Fel $\mathrm{d} 4$ it should be mentioned that the protein used in this study was a recombinant protein produced in E. coli. Fel d 4 has two potential N-glycosylation sites at aa 51 and aa 66. Glycosylation at this sites may enhance the interaction with HSPGs as is known from viral cell entry (Raman et al. 2016). In addition, no specific ligand of Fel d 4 is known at the moment. However, ligands may influence receptor binding which may also lead to use of different or additional receptors.

\section{Materials and methods}

\section{Cell culture}

HeLa, CHO-K1 and glycosaminoglycan (GAG)-deficient CHO-K1 mutant pgsA-745 cells (Esko et al. 1985) were purchased from ATCC.
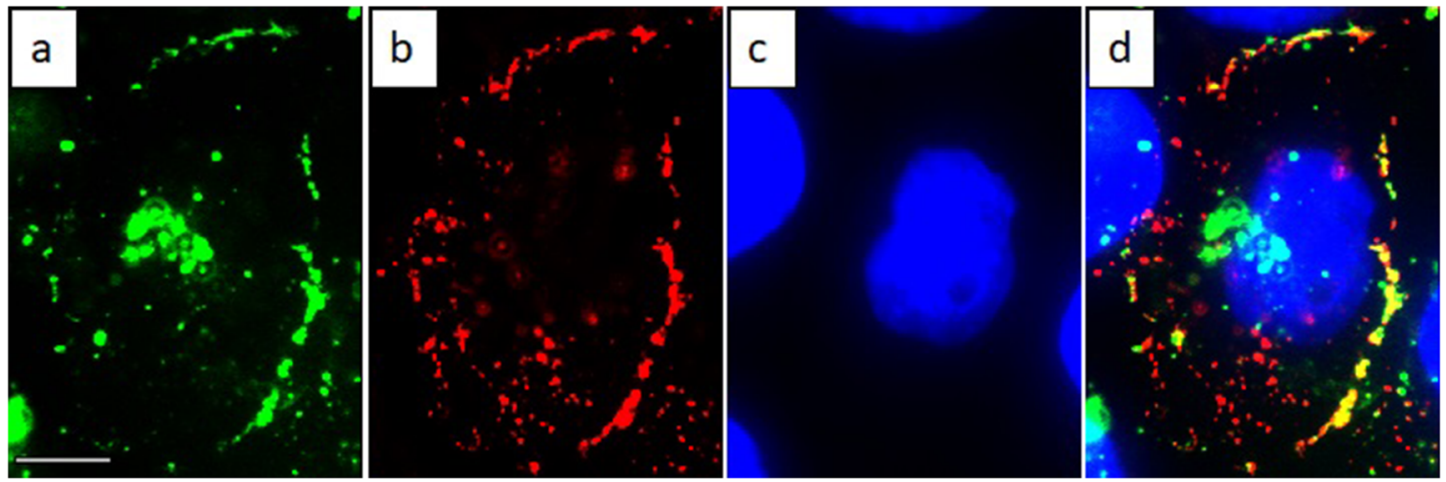

Figure 10: Colocalization of BLG (a) and heparan sulphate (b) on the plasma membrane of a HeLa cell. Nuclei (c) were stained with DAPI postfixation. Merge of all channels (d). Scale bar is $10 \mu \mathrm{m}$. 
All cell lines were grown in DMEM/Ham's F12 medium (Gibco, Thermo Fisher Science, Austria, Vienna) supplemented with 10\% FCS, 2 mM glutamine, $100 \mathrm{U} / \mathrm{mL}$ penicillin and $100 \mu \mathrm{g} / \mathrm{mL}$ streptomycin (further abbreviated "growth medium") and passaged in 2 to 3-day intervals.

\section{Biotin and SDAD-labelling of lipocalin baits}

Lipocalins beta-Lactoglobulin (BLG) and Fel d 4 were simultaneously labelled with Sulfo-NHS-SS-Diazirine (SDAD) photoactivatable crosslinker and Sulfo-NHS-LC-Biotin (both from Thermo Scientific, Austria, Vienna). Labelling efficiency was measured as biotin incorporation by a HABAbiotinylation-assay (Thermo Scientific) at 1-2 biotins per protein molecule. SDAD-labelling was estimated to be equally efficient due to similar molecular weight and identical reaction chemistry. Both StrepTactin-binding and crosslinking activity were successfully tested (not shown).

\section{HeLa membrane preparation}

HeLa cells grown to confluency were washed in PBS and incubated in serum-free growth medium for another 2 hours. Then, cells were washed in ice-cold PBS and harvested using a cell scraper. Cells were collected by centrifugation and the pellet resuspended in cold lysis buffer ( $250 \mathrm{mM}$ sucrose, $1 \mathrm{mM}$ EDTA, $10 \mathrm{mM}$ HEPES pH 7.4 supplemented with protease inhibitors). Cells were lysed mechanically by glass beads in a mixer mill (Retsch MM 400, Germany, Haan) set to $25 \mathrm{~Hz}$ for $3 \mathrm{~min}$. Membranous compounds were pelleted by ultracentrifugation at $100000 \mathrm{~g}$ at $4{ }^{\circ} \mathrm{C}$ for 1 hour. The pellet was resuspended in buffer ( $250 \mathrm{mM}$ sucrose, $1 \mathrm{mM} \mathrm{MgCl} 2,10 \mathrm{mM} \mathrm{HEPES} \mathrm{pH} \mathrm{7.4),} \mathrm{layered}$ onto sucrose density gradient ranging from $28-43 \%$ and centrifuged in a swinging bucket rotor overnight at $100000 \mathrm{~g}$. Plasma membrane fraction was collected and protein concentration was determined by Bradford assay.

\section{Isolation and identification of crosslinked proteins from HeLa membranes}

Ten $\mu$ g of labelled lipocalin bait were combined with $100 \mu \mathrm{g}$ of HeLa cell membranes in $20 \mathrm{mM}$ sodium phosphate $\mathrm{pH}$ 7.4. After 1 hour of incubation at room temperature, crosslinking was induced by UV irradiation at $365 \mathrm{~nm}$ for $5 \mathrm{~min}$. Thereafter, the complexes were solubilized by boiling in $1 \%$ sodium dodecylsulphate (SDS) and diluted 10 fold in wash buffer ( $50 \mathrm{mM}$ Tris $\mathrm{pH} 7.4,500 \mathrm{mM}$ urea, $500 \mathrm{mM} \mathrm{NaCl}, 1 \%$ Triton X-100). Lipocalin bait-prey complexes were pulled down on StrepTactin sepharose beads (IBA Lifesciences, Germany, Göttingen), extensively washed and finally eluted by reductive cleavage of SDAD's disulphide bond with $50 \mathrm{mM}$ dithiothreitol (DTT). Supernatants were mixed with $5 \times$ Laemmli sample buffer and boiled for $5 \mathrm{~min}$ at $95^{\circ} \mathrm{C}$. These eluates were then run on a $12 \%$ polyacrylamide gel and visualized by mass spectrometry-compatible silver staining. Proteins bands were excised and identified by mass spectrometry (see supplementary information).

\section{Production and purification of lipocalins and HSP90}

Recombinant Lcn-1 was produced as described previously (Holzfeind and Redl 1994). A codon-optimized Fel d 4 gene was synthesized
(GenScript, USA, Piscataway Township), cloned into Qiagen's pQE70 expression plasmid, produced and purified in M15 E. coli strain according to the manufacturer's instructions (QIAexpressionist). BLG used in this study originated from bovine milk (L7880, Sigma-Aldrich, Austria, Vienna) and was further purified by gel filtration. The gene encoding HSP90 was amplified from HeLa cDNA (attaching an Nterminal Strep-tag via PCR), cloned into the pET21d+ expression plasmid and expressed in Rosetta(DE3) cells.

\section{Lipocalin-HSP90 co-affinity precipitation experiments}

Recombinant Strep-tagged HSP90 was directly bound to magnetic StrepTactin beads (MagStrep "type 3" XT beads, IBA Lifesciences) from clarified $E$. coli lysate. The HSP90-loaded beads were washed extensively in PBS before BLG or Fel d 4 were added at a final concentration of $25 \mu \mathrm{g} / \mathrm{mL}$ in PBS buffer. The reactions were incubated for 1 hour at room to allow binding of lipocalins to HSP90. Afterwards, beads were washed in PBS thrice before bound HSP90 was eluted in $50 \mathrm{mM}$ D-biotin in TBS (100 mM Tris pH 8.0, $150 \mathrm{mM} \mathrm{NaCl}$ ). Samples collected from supernatant post-incubation, final washing step and eluate were analysed by Sodium dodecyl sulfate polyacrylamide gel electrophoresis (SDS-Page). Two control experiments were done applying each protein (HSP90 or lipocalin) alone to StrepTactin beads.

\section{Heparin affinity chromatography}

Lipocalins (Lcn-1, BLG and Fel d 4) in low salt buffer (buffer A: 20 mM sodium phosphate $\mathrm{pH}$ 7.4) were applied to a $2 \mathrm{~mL}$ heparin sepharose column (Heparin Sepharose 6 FastFlow, GE Healthcare, Austria, Vienna) connected to an ÄKTA prime chromatography system (Amersham Pharmacia Biotech, UK, Little Chalfont). Analysis was performed at a flow rate of $1 \mathrm{~mL} / \mathrm{min}$. Salt concentration was measured by conductivity and protein concentration by UV absorbance at $280 \mathrm{~nm}$. Samples were loaded and washed under low salt conditions (16 min at 0\% buffer B: $20 \mathrm{mM}$ sodium phosphate $\mathrm{pH}$ 7.4, $500 \mathrm{mM}$ sodium chloride) and eluted by a linear salt gradient (0 to $100 \%$ B over $8 \mathrm{~min}$ ).

\section{Fluorescence labelling of Lipocalins}

BLG was labelled with an 8-fold molar excess of NHS-Carboxyfluorescein (Sigma) in PBS for 1 hour at room temperature. Lcn-1 and Fel d 4 were labelled with a 5 -fold molar excess of Hilyte Fluor 594, SE (Anaspec, Germany, Göttingen) in PBS for 1 hour at room temperature. Then, coupling reactions were quenched and protein-dye conjugates separated from unreacted dye by diafiltration. Degree of labelling was about 1.5 and 1 dye molecules for BLG and Lcn-1/Fel d 4 labelling reactions respectively.

\section{Fluorescence microscopy}

One day prior to experiments, $2.5 \times 10^{4} \mathrm{HeLa}$ or Chinese hamster ovary (CHO) cells were settled in 4-well chamber slides (Nunc Lab-Tek, Thermo Scientific) in $500 \mu \mathrm{l}$ of growth medium. The next morning, cells were washed in PBS+ (PBS supplemented with $1 \mathrm{mM}$ each of $\mathrm{MgCl}_{2}$ and $\mathrm{CaCl}_{2}$ ), incubated in serum free medium and treated as described below. Afterwards, samples were washed, fixed in $4 \%$ paraformaldehyde, 
counterstained with DAPI and imaged on an Axioplan fluorescence microscope (Carl Zeiss, Germany, Jena) equipped with an AcioCam MR3 camera and filter sets 365/445, 470/540 and 565/620. All image processing and analysis was done on Axiovision (Carl Zeiss), Microsoft PowerPoint (Microsoft Corp.) and by ImageJ (imagej.net).

\section{Heparin, heparinase and sodium chlorate treatment of HeLa cells}

HeLa cells were treated with PBS (control), $100 \mu \mathrm{g} / \mathrm{mL}$ heparin (from porcine intestinal mucosa, Sigma), 0.5, 2.0 or $10.0 \mathrm{U} / \mathrm{mL}$ heparinase I/ III blend (Sigma) in serum-free growth medium for 30 min before $25 \mu \mathrm{g} / \mathrm{mL}$ (equalling $1.25 \mu \mathrm{M}$ ) fluorescently labelled BLG or Fel d 4 were added for 2 hours.

For chlorate experiments, HeLa cells were cultured overnight in growth medium without (control) or with $30 \mathrm{mM} \mathrm{NaClO}$. The next morning, cells were washed with PBS and incubated in serum-free growth medium for $30 \mathrm{~min}$ before labelled lipocalins were added as indicated above.

\section{CHO K1 wild-type and GAG-deficient pgsA-745 mutant cells}

CHO K1 wild-type (control) and GAG-deficient pgsA-745 mutant cells were incubated with $25 \mu \mathrm{g} / \mathrm{mL}$ (equalling $1.25 \mu \mathrm{M}$ ) fluorescently labelled BLG or Fel d 4 in serum-free medium for 2 hours and then processed for fluorescence microscopy.

\section{Colocalization of cell surface heparan sulphate and BLG}

HeLa cells were simultaneously incubated with CarboxyfluoresceinBLG $(25 \mu \mathrm{g} / \mathrm{mL}$ equalling $1.25 \mu \mathrm{M})$ and $1 \mu \mathrm{g}$ of biotinylated heparan sulphate antibody (amsbio F58-10E4, AMS Biotechnology Ltd, UK, Abingdon) coupled to AlexaFluor594-Streptavidin (Thermo Scientific) for 1 hour in serum-free growth medium. Afterwards, samples were washed, fixed and counterstained with DAPI. Imaging was performed as described above.

Acknowledgements: This work was financially supported by the Austrian Science Foundation (FWF) grant P 27408. We thank Florentine Marx and Ingo Bauer, Institute of Molecular Biology, MUI Biocenter, for helpful discussions and Petra Merschak for technical assistance.

Conflict of interest statement: The authors declare that there are no competing interests associated with the manuscript.

\section{References}

Akerstrom, B., Borregaard, N., Flower, D.R., and Salier, J.P. (2006). Lipocalins: an introduction. In: Akerstrom, B. (Ed.). Lipocalins. CRC Press, Boca Raton, FL, USA, pp. 1-5.
Bijari, N., Ghobadi, S., and Derakhshandeh, K. (2019). $\beta$ lactoglobulin-irinotecan inclusion complex as a new targeted nanocarrier for colorectal cancer cells. Res. Pharmaceut. Sci. 14: 216-227.

Binda, C., Génier, S., Cartier, A., Larrivée, J.F., Stankova, J., Young, J.C., and Parent, J.L. (2014). A G protein-coupled receptor and the intracellular synthase of its agonist functionally cooperate. J. Cell Biol. 204: 377-393.

Brennan, P.A. and Kendrick, K.M. (2006). Mammalian social odours: attraction and individual recognition. Phil. Trans. Biol. Sci. 361: 2061-2078.

Burke, B.J., Redondo, C., Redl, B., and Findlay, J.B.C. (2006). Lipocalin receptors: into the Spotlight. In: Akerstrom, B. (Ed.). Lipocalins. CRC Press, Boca Raton, FL, USA, pp. 167-172.

Bzowska, M., Nogieć, A., Bania, K., Zygmunt, M., Zarębski, M., Dobrucki, J., and Guzik, K. (2017). Involvement of cell surface 90 kDa heat shock protein (HSP90) in pattern recognition by human monocyte-derived macrophages. J. Leukoc. Biol. 102: 763-774.

Chakraborty, S., Kaur, S., Guha, S., and Batra, S.K. (2012). The multifaceted roles of neutrophil gelatinase associated lipocalin (NGAL) in inflammation and cancer. Biochim. Biophys. Acta 1826: 129-169.

Chamero, P., Marton, T.F., Logan, D.W., Flanagan, K., Cruz, J.R., Saghatelian, A., Cravatt, B.F., and Stowers, L. (2007). Identification of protein pheromones that promote aggressive behaviour. Nature 450: 899-902.

Charron, J.B.F., Ouellet, F., Houde, M., and Sarhan, F. (2008). The plant Apolipoprotein D ortholog protects Arabidopsis against oxidative stress. BMC Plant Biol. 8: 86.

Christensen, E.I. and Birn, H. (2002). Megalin and cubilin: multifunctional endocytic receptors. Nat. Rev. Mol. Cell Biol. 3: 256-266.

Christianson, H.C. and Belting, M. (2014). Heparan sulfate proteoglycan as a cell-surface endocytosis receptor. Matrix Biol. 35: 51-55.

Conde, J., Scotece, M., Gómez, R., López, V., Gómez-Reino, J.J., Lago, F., and Gualillo, O. (2011). Adipokines: biofactors from white adipose tissue. A complex hub among inflammation, metabolism, and immunity. Biofactors 37: 413-420.

Correnti, C. and Strong, R.K. (2012). Mammalian siderophores, siderophore-binding lipocalins, and the labile iron pool. J. Biol. Chem. 287: 13524-13531.

Crowe, L.B., Hughes, P.F., Alcorta, D.A., Osada, T., Smith, A.P., Totzke, J., Loiselle, D.R., Lutz, I.D., Gargesha, M., Roy, D., et al. (2017). A fluorescent $\mathrm{Hsp} 90$ probe demonstrates the unique association between extracellular Hsp90 and malignancy in vivo. ACS Chem. Biol. 12: 1047-1055.

Devireddy, L.R., Gazin, C., Zhu, X., and Green, M.R. (2005). A cellsurface receptor for lipocalin $24 \mathrm{p} 3$ selectively mediates apoptosis and iron uptake. Cell 123: 1293-1305.

Esko, J.D., Stewart, T.E., and Taylor, W.H. (1985). Animal cell mutants defective in glycosaminoglycan biosynthesis. Proc. Natl. Acad. Sci. USA 82: 3197-3201.

Fan, T.C., Chang, H.T., Chen, I.W., Wang, H.Y., and Chang, M.D.T. (2007). A heparan sulfate-facilitated and raft-dependent macropinocytosis of eosinophil cationic protein. Traffic 8: 17781795.

Fittipaldi, A., Ferrari, A., Zoppé, M., Arcangeli, C., Pellegrini, V., Beltram, F., and Giacca, M. (2003). Cell membrane lipid rafts mediate caveolar endocytosis of HIV-1 Tat fusion proteins. J. Biol. Chem. 278: 34141-34149. 
Flower, D.R. (2000). Beyond the superfamily: the lipocalin receptors. Biochim. Biophys. Acta Protein Struct. Mol. Enzymol. 1482: 327-336.

Fluckinger, M., Merschak, P., Hermann, M., Haertlé, T., and Redl, B. (2008). Lipocalin-interacting-membrane-receptor (LIMR) mediates cellular internalization of $\beta$-lactoglobulin. Biochim. Biophys. Acta 1778: 342-347.

Ganfornina, M.D., Do Carmo, S., Lora, J.M., Torres-Schumann, S., Vogel, M., Allhorn, M., González, C., Bastiani, M.J., Rassart, E., Sanchez, D. (2008). Apolipoprotein D is involved in the mechanisms regulating protection from oxidative stress. Aging Cell 7: 506-515.

Gonzalez-Gronow, M., Selim, M.A., Papalas, J., and Pizzo, S.V. (2009). GRP78: a multifunctional receptor on the cell surface. Antioxidants Redox Signal. 11: 2299-2306.

Harada, Y., Garenáux, E., Nagatsuka, T., Uzawa, H., Nishida, Y., Sato, C., and Kitajima, K. (2014). Interaction of 70-kDa heat shock protein with glycosaminoglycans and acidic glycopolymers. Biochem. Biophys. Res. Commun. 453: 229-234.

Holzfeind, P. and Redl, B. (1994). Structural organization of the gene encoding the human lipocalin tear prealbumin and synthesis of the recombinant protein in Escherichia coli. Gene 139: 177-183.

Itoh, H. and Tashima, Y. (1993). Domain structure of the 90-kDa stress protein: heparin- and antibody-binding domain. Int. J. Biochem. 25: 157-161.

Johnson, E.E. and Wessling-Resnick, M. (2012). Iron metabolism and the innate immune response to infection. Microb. Infect. 14: 207-216.

Kawaguchi, R., Yu, J., Honda, J., Hu, J., Whitelegge, J., Ping, P., Wiita, P., Bok, D., and Sun, H. (2007). A membrane receptor for retinol binding protein mediates cellular uptake of vitamin A. Science 315: 820-825.

Kim, W.S., Wong, J., Weickert, C.S., Webster, M.J., Bahn, S., and Garner, B. (2009). Apolipoprotein-D expression is increased during development and maturation of the human prefrontal cortex. J. Neurochem. 109: 1053-1066.

Koistinen, H., Hautala, L.C., Seppälä, M., Stenman, U.H., Laakkonen, P., and Koistinen, R. (2009). The role of glycodelin in cell differentiation and tumor growth. Scand. J. Clin. Lab. Investig. 69: 452-459.

Kontopidis, G., Holt, C., and Sawyer, L. (2004). $\beta$-Lactoglobulin: binding properties, structure, and function. J. Dairy Sci. 87: 785-796.

Langelueddecke, C., Roussa, E., Fenton, R.A., Wolff, N.A., Lee, W.K., and Thévenod, F. (2012). Lipocalin-2 (24p3/neutrophil gelatinase-associated lipocalin (NGal) receptor is expressed in distal nephron and mediates protein endocytosis. J. Biol. Chem. 287: 159-169.

Lechner, M., Wojnar, P., and Redl, B. (2001). Human tear lipocalin acts as an oxidative-stress-induced scavenger of potentially harmful lipid peroxidation products in a cell culture system. Biochem. J. 356: 129-135.

Leheste, J.R., Rolinski, B., Vorum, H., Hilpert, J., Nykjaer, A., Jacobsen, C., Aucouturier, P., Moskaug, J.Ø., Otto, A., Christensen, E.I., et al. (1999). Megalin knockout mice as an animal model of low molecular weight proteinuria. Am. J. Pathol. 155: 1361-1370.

Léonetti, M., Gadzinski, A., and Moine, G. (2010). Cell surface heparan sulfate proteoglycans influence MHC class II-restricted antigen presentation. J. Immunol. 185: 3847-3856.
Ménoret, A. and Bell, G. (2000). Purification of multiple heat shock proteins from a single tumor sample. J. Immunol. Methods 237: 119-130.

Mounkes, L.C., Zhong, W., Cipres-Palacin, G., Heath, T.D., and Debs, R.J. (1998). Proteoglycans mediate cationic liposome-DNA complex-based gene delivery in vitro and in vivo. J. Biol. Chem. 273: 26164-26170.

Mulligan, K.A., Fuerer, C., Ching, W., Fish, M., Willert, K., and Nusse, R. (2012). Secreted Wingless-interacting molecule (Swim) promotes long-range signaling by maintaining Wingless solubility. Proc. Natl. Acad. Sci. USA 109: 370-377.

Najyb, O., Brissette, L., and Rassart, E. (2015). Apolipoprotein D internalization is a basigin-dependent mechanism. J. Biol. Chem. 290: 16077-16087.

Okazaki, Y., Ohno, H., Takase, K., Ochiai, T., and Saito, T. (2000). Cell surface expression of calnexin, a molecular chaperone in the endoplasmic reticulum. J. Biol. Chem. 275: 35751-35758.

Olsson, M.G., Olofsson, T., Tapper, H., and Akerstrom, B. (2008). The lipocalin alpha1-microglobulin protects erythroid $\mathrm{K} 562$ cells against oxidative damage induced by heme and reactive oxygen species. Free Radic. Res. 42: 725-736.

Ori, A., Wilkinson, M.C., and Fernig, D.G. (2008). The heparanome and regulation of cell function: structures, functions and challenges. Front. Biosci. 13: 4309-4338.

Pan, H.F., Leng, R.X., Zhang, N., Tao, J.H., and Ye, D.Q. (2011). Role and therapeutic potential of Glycodelin A in systemic lupus erythematosus. Rheumatol. Int. 31: 563-565.

Papes, F., Logan, D.W., and Stowers, L. (2010). The vomeronasal organ mediates interspecies defensive behaviors through detection of protein pheromone homologs. Cell 141: 692-703.

Park, H., Kim, M., Kim, H.J., Lee, Y., Seo, Y., Pham, C.D., Lee, J., Byun, S.J., and Kwon, M.H. (2017). Heparan sulfate proteoglycans (HSPGs) and chondroitin sulfate proteoglycans (CSPGs) function as endocytic receptors for an internalizing anti-nucleic acid antibody. Sci. Rep. 7: 14373.

Payne, C.K., Jones, S.A., Chen, C., and Zhuang, X. (2007). Internalization and trafficking of cell surface proteoglycans and proteoglycan-binding ligands. Traffic 8: 389-401.

Podyma-Inoue, K.A., Moriwaki, T., Rajapakshe, A.R., Terasawa, K., and Hara-Yokoyama, M. (2016). Characterization of heparan sulfate proteoglycan-positive recycling endosomes isolated from glioma cells. Cancer Genom. Proteom. 13: 443-452.

Poon, G.M.K. and Gariépy, J. (2007). Cell-surface proteoglycans as molecular portals for cationic peptide and polymer entry into cells. Biochem. Soc. Trans. 35: 788-793.

Rachmilewitz, J., Borovsky, Z., Riely, G.J., Miller, R., and Tykocinski, M.L. (2003) Negative regulation of T cell activation by placental protein 14 is mediated by the tyrosine phosphatase receptor CD45. J. Biol. Chem. 278: 14059-14065.

Raman, R., Tharakaraman, K., Sasisekharan, V., and Sasisekharan, R. (2016). Glycan-protein ineractions in viral pathogenesis. Curr. Opin. Struct. Biol. 40: 153-162.

Redondo, C., Vouropoulou, M., Evans, J., and Findlay, J.B.C. (2008). Identification of the retinol-binding protein (RBP) interaction site and functional state of RBPs for the membrane receptor. Faseb J. 22: 1043-1054.

Ruiz, M., Sanchez, D., Correnti, C., Strong, R.K., and Ganfornina, M.D. (2013). Lipid-binding properties of human ApoD and Lazarillorelated lipocalins: functional implications for cell differentiation. FEBS J. 280: 3928-3943. 
Sawyer, L. and Kontopidis, G. (2000). The core lipocalin, bovine $\beta$-lactoglobulin. Biochim. Biophys. Acta Protein Struct. Mol. Enzymol. 1482: 136-148.

Shafaei, Z., Ghalandari, B., Vaseghi, A., Divsalar, A., Haertlé, T., Saboury, A.A., and Sawyer, L. (2017). $\beta$-Lactoglobulin: an efficient nanocarrier for advanced delivery systems. Nanomedicine 13: 1685-1692.

Smith, W., Butler, A.J.L., Hazell, L.A., Chapman, M.D., Pomés, A., Nickels, D.G., and Thomas, W.R. (2004). Fel d 4, a cat lipocalin allergen. Clin. Exp. Allergy 34: 1732-1738.

Snigireva, A.V., Vrublevskaya, V.V., Afanasyev, V.N., and Morenkov, O.S. (2015). Cell surface heparan sulfate proteoglycans are involved in the binding of $\mathrm{Hsp} 90 \alpha$ and $\mathrm{Hsp} 90 \mathrm{\beta}$ to the cell plasma membrane. Cell Adhes. Migrat. 9: 460-468.

Soltys, B.J. and Gupta, R.S. (1996). Immunoelectron microscopic localization of the $60-\mathrm{kDa}$ heat shock chaperonin protein (Hsp60) in mammalian cells. Exp. Cell Res. 222: 16-27.

Suk, K. (2012). Unexpected role of lipocalin-type prostaglandin D synthase in brain: regulation of glial cell migration and morphology. Cell Adhes. Migrat. 6: 160-163.

Tai, C.S., Chen, Y.Y., and Chen, W.L. (2016). $\beta$-Lactoglobulin influences human immunity and promotes cell proliferation. BioMed. Res. Int. 2016: 7123587
Wittrup, A., Zhang, S.H., Svensson, K.J., Kucharzewska, P., Johansson, M.C., Mörgelin, M., and Belting, M. (2010). Magnetic nanoparticle-based isolation of endocytic vesicles reveals a role of the heat shock protein GRP75 in macromolecular delivery. Proc. Natl. Acad. Sci. USA 107: 13342-13347.

Wojnar, P., Lechner, M., Merschak, P., and Redl, B. (2001). Molecular cloning of a novel lipocalin-1 interacting human cell membrane receptor using phage display. J. Biol. Chem. 276: 20206-20212.

Yang, J., Goetz, D., Li, J.Y., Wang, W., Mori, K., Setlik, D., Du, T., Erdjument-Bromage, H., Tempst, P., Strong, R., et al. (2002). An iron delivery pathway mediated by a lipocalin. Mol. Cell 10: 1045-1056.

Zhao, H., Konishi, A., Fujita, Y., Yagi, M., Ohata, K., Aoshi, T., Itagaki, S., Sato, S., Narita, H., Abdelgelil, N.H., et al. (2012). Lipocalin 2 bolsters innate and adaptive immune responses to blood-stage malaria infection by reinforcing host iron metabolism. Cell Host. Microbe. 12: 705-716.

Zhu, W., Li, J., and Liang, G. (2011). How does cellular heparan sulfate function in viral pathogenicity? Biomed. Environ. Sci. 24: 81-87.

Supplementary Material: The online version of this article offers supplementary material (DOI:10.1515/hsz-2020-0132). 